\title{
Minha Guirlanda de Poemas: 31 TraduÇões Inéditas
}

\author{
João Angelo Oliva Neto*
}

\section{A. EPIGRAMAS GREGOS}

Lírica convivial

1. Anacreonte de Teos (570 - 488 a.C.), fragmento 2 (W): banquetes não são ocasião de "falar" de sangrentas guerras, entenda-se, não são lugar para cantos épicos, mas líricos, sobre o amor e o vinho que o tempera.

* Professor do Departamento de Letras Clássicas da Universidade de São Paulo. 


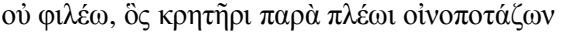

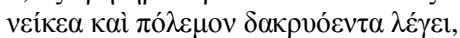

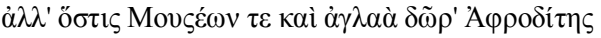

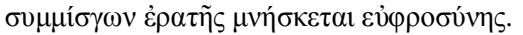

Não amo quem, bebendo ante a cratera cheia, de lutas fala e guerras lacrimosas,

mas quem, das Musas dons brilhantes e Afrodite unindo, lembra o gozo e a amável festa.

\section{Epigramas fúnebres}

2. Antologia Palatina, 7, 199 (Timnes, séc. III d.C.): lamento pela morte do bichinho de estimação, o passarinho:

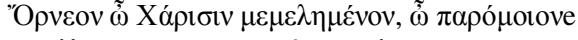

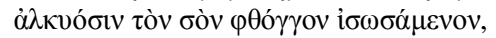

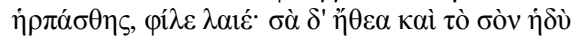

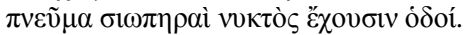

Passarinho, no qual as Graças cuidam, quase igual à alcíone no som que entoas!

Foste levado, ó melro meu: teu modo e doce voz o caminho os tem da noite mudo.

3. Antologia Palatina, 7, 80 - Calímaco de Cirene (300-240 a.C.) Epigramas, 2 (Pf.): lamento pela morte do amigo, cuja falta é suprida pela doçura dos poemas que deixou; o Hades, reino dos mortos, não vai silenciá-los.

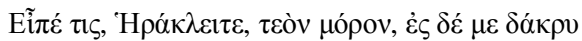

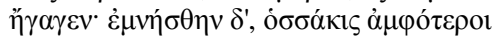

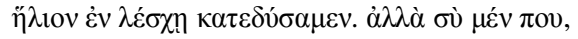

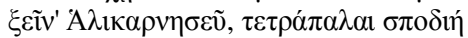

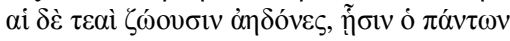

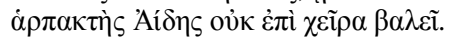

Alguém contou teu fim, Heráclito, e às lágrimas levou-me. Lembro o quanto em falas nós embalamos o sol e agora tu, meu hóspede de Halicarnasso, há muito só és cinza.

Mas vivem, rouxinóis, teus cantos, em que o Hades devora-tudo - a mão não vai tocar.

4. Antologia Palatina, 7, 476 - Meléagro de Gádara (séc. I a.C.): lamento pela morte da amada.

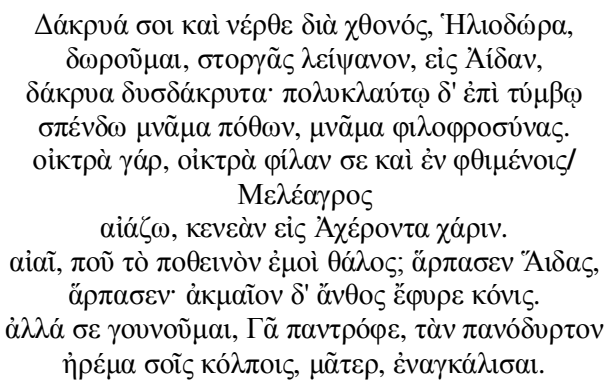

\author{
Lágrimas através da terra até no Hades, \\ Heliodora, - de amor um resto - envio-te. \\ Lágrimas de amargor na tumba tão chorada \\ verto, lembrança de desejo e afeto. \\ Cara na morte até, triste, triste Meléagro \\ choro-te, vão tributo ao Aqueronte. \\ Ai, meu broto onde está, tão desejável? Hades \\ raptou-a e a flor no viço o pó conspurca. \\ Mas eu te imploro, Terra, ó mãe, nutriz de tudo: \\ a que sofreu, põe suave em teu regaço.
}

\section{Epigrama pederástico}

5. Antologia Palatina, 12, 71 - Calímaco de Cirene (300-240 a.C.), Epigramas, 30 (Pf.): a medúsica beleza: um rapaz, ao encontrar após certo tempo um amigo, esquálido e desolado, percebe que o amigo foi acometido do mesmo mal que antes o acometera: apaixonou-se pelo jovem Euxíteo depois de simplesmente olhá-lo.

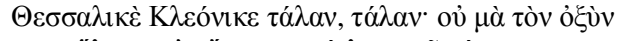

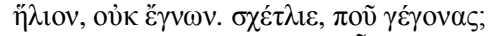

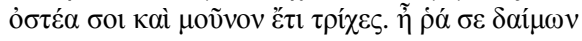

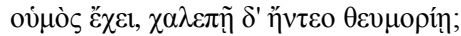

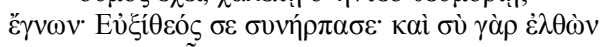

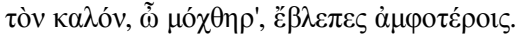

\begin{abstract}
Cleônico Tessálio, ó dó, que dó: por este sol, não te conheci! Triste, onde andaste? Osso e cabelo és só! Será que te apanhou meu fado, ombreias contra dura sina? Já sei: arrebatou-te Euxíteo: chegaste, ó pobre, e ao belo olhaste co'os dois olhos.
\end{abstract}




\section{Epigramas eróticos}

6. Antologia Palatina, 5, 107 - Filodemo de Gádara (séc. I a.C.): no amor, na guerra, ri melhor quem ri por último. Sendo ainda poeta, pode celebrizar a própria vitória na posteridade.

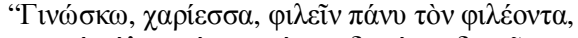

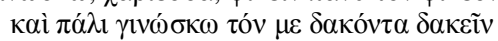

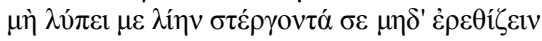

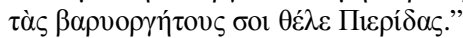

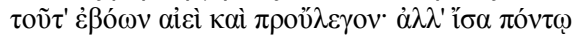
'Ioví $\mu$

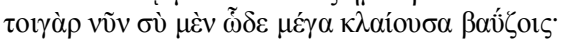

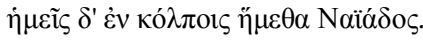

\author{
"Sei bem, ó minha graça, amar a quem me ama \\ e sei morder também a quem me morde. \\ Não me firas, que bem te quero, nem provoques \\ a ira das Piérides tão grave." \\ Isto só fiz gritar, preveni, mas qual mar \\ Jônio minhas palavras não ouvistes. \\ E tu agora a lamentar-te muito choras, \\ enquanto ao colo deito-me de Náiade.
}

7. Antologia Palatina, 5, 6 - Calímaco de Cirene (300-240 a.C.), Epigramas, 25 (Pf.): juras de amor nada valem.

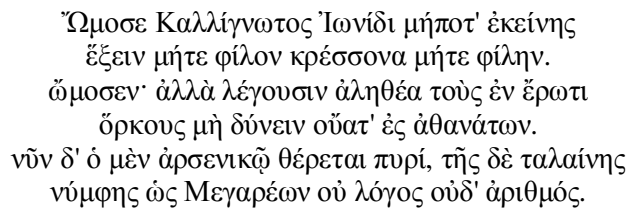

\author{
Calignoto jurou a Iônide jamais \\ querer amigo, mais que a ela, e amiga. \\ Jurou. Mas, dizem, juras no amor verdadeiras \\ aos ouvidos de um deus não vão. Em chamas \\ ele arde por um jovem. Dela, pobre noiva, \\ qual Megários, não há quem fale ou lembre.
}

8. Antologia Palatina, 5, 24 - Meléagro de Gádara (séc. I a.C.): no amor não se faz o que se sabe que se deve fazer.

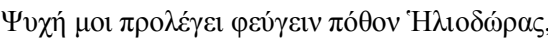

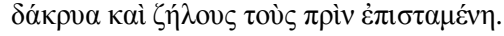

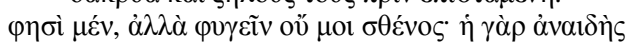

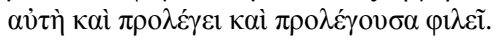

\author{
Minh' alma avisa: "fuja à paixão de Heliodora", \\ pois lágrimas conhece e o ciúme antigo. \\ Diz, mas forças não tenho. A própria sem-vergonha \\ também avisa e, enquanto avisa, me ama.
}

9. Antologia Palatina, 12, 172 - Eveno (data incerta): por que rimar amor e dor?

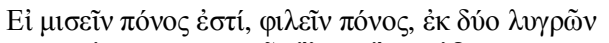

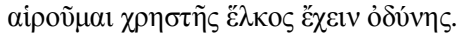

\author{
Se é pena odiar, se amar é pena, de dois males \\ escolho a chaga da benigna dor.
}

10. Antologia Palatina, 5, 29 - Calíctor (séc. III a.C.): não é doce o amor venal.

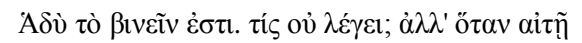

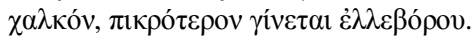

Doce é fazer amor. Quem nega? Mas se for
pagando, é mais amargo do que heléboro.

\section{Epigrama invectivo e jocoso}

11. Antologia Palatina, 11, 321- Filipo (séc. I d. C.): referindo-se à poética antiga, o poema ataca a atividade dos gramáticos e filólogos da Biblioteca de Alexandria: "Filhos

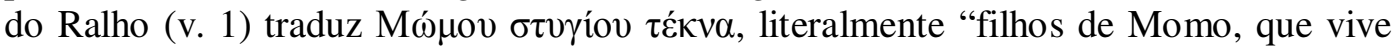
no Estige": Momo é divindade infernal, filho da noite e personificação da maledicência. Zenódoto de Éfeso (séculos IV-III a.C.) foi gramático, assim como o poeta Calímaco de Cirene, e primeiro diretor da Biblioteca de Alexandria. Filipe, além de citar Calímaco (v. 3), menciona os Telquines ( $\tau \varepsilon \lambda \chi \tilde{i} v \varepsilon \varsigma \beta i ́ \beta \lambda \omega v$, "telquines dos livros", v. 2), demônios que habitam o mar Egeu, com que Calímaco, justamente no Aos Telquines (fragmento 1, Pfeiffer), se defende atacando os detratores, dizendo ainda que "estrilavam"

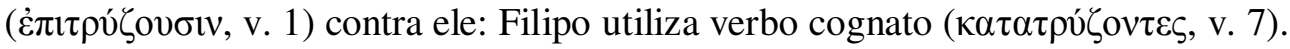


Pallentes procul hinc abite curae, quidquid uenerit obuium loquamur morosa sine cogitatione.

Misce dimidios, puer, trientes, quales Pythagoras dabat Neroni, misce, Dindyme, sed frequentiores: possum nil ego sobrius; bibenti succurrent mihi quindecim poetae. Da nunc basia, sed Catulliana: quae si tot fuerint quot ille dixit, donabo tibi Passerem Catulli.

\section{Epigramas 4, 14.}

Sili, Castalidum decus sororum, qui periuria barbari furoris ingenti premis ore perfidosque astus Hannibalis leuisque Poenos magnis cedere cogis Africanis: paulum seposita seueritate, dum blanda uagus alea December incertis sonat hinc et hinc fritillis et ludit tropa nequiore talo, nostris otia commoda Camenis, nec torua lege fronte, sed remissa, lasciuis madidos iocis libellos. Sic forsan tener ausus est Catullus magno mittere Passerem Maroni

\author{
Longe daqui parti, cuidados lívidos \\ quero falar o que me der na telha \\ sem demorada consideração. \\ Mistura, jovem, copos meio a meio \\ como Pitágoras a Nero dava; \\ mistura, agora mais freqüentes, Díndimo, \\ que sóbrio eu nada posso: se beber, \\ quinze poetas vêm-me socorrer. \\ Beijos me dá, porém Catulianos: \\ se tantos forem, quantos ele disse, \\ te dou o Passarinho de Catulo.
}

15. Epigramas, 3, 25: nos tratados de poética e retórica da Antigüidade, dizia-se que um discurso inepto era frio ou produzia frio, como se lê em Aristóteles (Retórica, 3, 3, 3 = 1406a), "Assim, os que usam elocução poética inconveniente produzem ridículo e frieza", e Quintiliano (Instituições Oratórias, 6, 1, 37): "Pois imperícia, rusticidade, dureza e grosseria produzem às vezes frio". Marcial serve-se positivamente de tal frialdade.

\footnotetext{
Si temperari balneum cupis feruens, Faustine, quod uix Iulianus intraret, roga lauetur rhetorem Sabineium. Neronianas is refrigerat thermas.
}

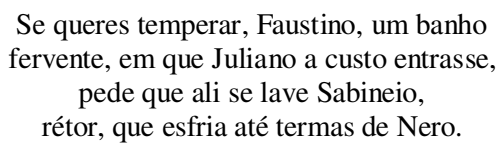

16. Epigramas, 10, 21: Sexto é poeta tão obscuro, tão difícil, que até mesmo os gramáticos Modesto e Clarano, comentadores e conhecedores de poesia, mal compreendem: só mesmo o deus Apolo, decifrador de enigmas, para entendê-los. Marão não é outro senão Públio Virgílio Marão, autor da Eneida, a quem Marcial, epigramatista convicto, considera inferior ao poeta neotérico Gaio Hélvio Cina, de que só restaram fragmentos. "Juiz" (v. 4, iudice, de iudex) é termo jurídico acolhido pela poética e designa a crítica que inclui precisamente "juízo", "julgamento" sobre que autores são melhores. Se Sexto é bom crítico, deverá considerar que Cina, autor de poemas ligeiros, é superior a Virgílio, autor de poema épico e grave, isto é, um "pesado", que é a Eneida.

Scribere te quae uix intellegat ipse Modestus et uix Claranus, quid, rogo, Sexte, iuuat?

Non lectore tuis opus est, sed Apolline libris: iudice te maior Cinna Marone fuit.

Sic tua laudentur sane: mea carmina, Sexte, grammaticis placeant, ut sine grammaticis.
Sexto por que te apraz compor o que Modesto, o que Clarano a custo compreendem?

Leitor teus livros não requerem, mas Apolo. Se és juiz, mais do que Marão foi Cina. Que assim se louvem teus poemas, Sexto: os meus, gramáticos deleitem, sem gramáticos. 
17. Epigramas, 3, 89: Na medicina antiga, ausência de humores era sinal de saúde. "Humor" tem aqui acepção etimológica: é líquido (daí "úmido") que, secretado pelo corpo, é responsável supostamente pelo estado físico e mental, donde provém o sentido atual de "humor". Eram quatro: sangue, bile amarela, fleuma (ou pituíta) e bile negra (ou atrabílis). Marcial explora jocosamente problemas do excesso de secura.

Utere lactucis et mollibus utere maluis: nam faciem durum, Phoebe, cacantis habes.
Ó Febe, come alface e come a malva lisa, que tens cara de quem só caga duro.

18. Epigramas, 1, 23: No mercado dos desejos eróticos, que eram os balneários em Roma, Cota apenas convidava a sua casa aqueles que eram bem dotados, o que não incluiu o poeta.

Inuitas nullum nisi cum quo, Cotta, lauaris et dant conuiuam balnea sola tibi.

Mirabar, quare numquam me, Cotta, uocasses: iam scio, me nudum displicuisse tibi.

\author{
Ninguém convidas, só com quem te lavas, Cota, \\ e só os banhos dão o teu conviva. \\ Admirava-me, Cota, o nunca me chamares: \\ agora sei que, nu, não te agradei.
}

\section{Epigramas 14, 18.}

Alea parua nuces et non damnosa uidetur; saepe tamen pueris abstulit illa natis.
Ingênua, lembra a noz um dadinho. Porém, de meninos ganhou muito cuzinho.

20. Epigramas, 4, 81: o pé da letra ou o tiro pela culatra.
Epigramma nostrum cum Fabulla legisset, negare nullam quo queror puellarum, semel rogata bisque terque neglexit preces amantis. Iam, Fabulla, promitte: negare iussi, pernegare non iussi.

\begin{abstract}
Fabula leu meu epigrama em que eu me queixo que menina alguma nega. Uma vez, duas, três a quis o amante, e os rogos dele ela negou. Fabula, diz sim!: mandei negar, não renegar!
\end{abstract}

\section{Epigrama programático}

21. Epigramas, 1, 4: sobre matéria e elocução próprias do gênero epigramático; nota-se a dissociação entre o caráter da persona epigramática e da pessoa do poeta.

Contigeris nostros, Caesar, si forte libellos, terrarum dominum pone supercilium.

Consueuere iocos uestri quoque ferre triumphi, materiam dictis nec pudet esse ducem.

Qua Thymelen spectas derisoremque Latinum, illa fronte precor carmina nostras legas. Innocuos censura potest permittere lusus: lasciua est nobis pagina, uita proba.

\begin{abstract}
Se acaso nos livrinhos meus tocares, César, descerra o cenho de senhor da Terra: toleram brincadeira até vossos Triunfos; não cora o chefe por dar mote aos ditos. Se a Tímele e a Latino derrisor assistes, co' rosto com que os vês lê meus poemas. Troças permita inócuas a censura: em mim a página é lasciva, proba a vida.
\end{abstract}

\section{Epigrama fúnebre}

22. Epigramas, 5, 34: lamento pela morte da escrava ainda criança.

Hanc tibi, Fronto pater, genetrix Flaccilla, puellam oscula commendo deliciasque meas,

paruola ne nigras horrescat Erotion umbras oraque Tartarei prodigiosa canis.

Impletura fuit sextae modo frigora brumae, uixisset totidem ni minus illa dies.

\footnotetext{
A ti Frontão meu pai, a ti, ó mãe Flacila confio esta menina (são meus beijos e delícias): que Erótion tão pequena as negras sombras não tema nem monstruosas bocas do cão do Tártaro. Completaria o sexto inverno se vivesse mais seis dias.
} 
Inter tam ueteres ludat lasciua patronos et nomen blaeso garriat ore meum.

Mollia non rigidus caespes tegat ossa nec illi, terra, grauis fueris: non fuit illa tibi.
Feliz com seus patrões tão velhos brinque e tente meu nome balbuciar na voz rouquinha.

Não dura relva os ossos tenros cubra e, terra!, não lhe peses, que em ti não pesou.

\section{Epigrama erótico}

23. Epigramas, 4, 21: recém-casada e virgem, Cleópatra protege-se do marido atirandose na piscina ("lago nítido"), que a faz parecer flores acomodadas em vasos de vidro e cristal e a ele só permite que da flor colha só beijos.

\author{
Primos passa toros et adhuc placanda marito \\ merserat in nitidos se Cleopatra lacus, \\ dum fugit amplexus. Sed prodidit unda latentem; \\ lucebat, totis cum tegeretur aquis: \\ condita sic puro numerantur lilia uitro, \\ sic prohibet tenuis gemma latere rosas. \\ Insilui mersusque uadis luctantia carpsi \\ basia: perspicuae plus uetuistis aquae.
}

\author{
Tentada pela vez primeira e do marido \\ ainda não domada, em lago nítido \\ Cleópatra mergulha por fugir a amplexos. \\ Mas traem as ondas quem se esconde: brilha \\ sob tanta água! Em puro vidro ocultos vêem-se \\ lírios; cristal delata a oculta rosa. \\ Salto e, submerso em vaga, relutantes colho \\ beijos: mais não deixastes, águas lúcidas!
}

\section{Epigrama pederástico e votivo.}

24. Epigramas, 1, 31: É poema votivo porque se assiste à oferenda dos próprios cabelos feita a Apolo por um rapazinho escravo, o amante passivo de seu senhor, - razão pela qual também é epigrama pederástico. Não só por isso, já que celebra em seguida, no irrealizável pedido ao deus, o derradeiro esplendor de beleza juvenil no adolescente, prestes a perder a graça feminina na pilosidade viril que lhe despontará. Não há invectiva, turpilóquio ou irrisão.
Hos tibi, Phoebe, uouet totos a uertice crines Encolpos, domini centurionis amor, grata Pudens meriti tulerit cum praemia pili. Quam primum longas, Phoebe, recide comas, dum nulla teneri sordent lanugine uoltus dumque decent fusae lactea colla iubae; utque tuis longum dominusque puerque fruantur muneribus, tonsum fac cito, sero uirum.
Os cachos todos de alto a baixo, Febo, imola-te Eumolpo, amor de seu senhor, Pudente, que, centurião, com jus chegara a primipilo. Depressa, Febo, longas corta as mechas, enquanto pêlo algum lhe mancha a tenra face e ao colo lácteo caem bem cabelos. E por que gozem mais senhor e jovem dotes teus, faze-o glabro cedo, e tarde um homem.

\section{OUTROS POETAS}

\section{Epigramas fúnebres e inscrições lapidares}

25. CIL, 13, 488: outro lamento pela morte do bicho de estimação, agora uma cadelinha. Aqui, o notável é que o epigrama é inscrição verdadeira (CIL, 13, 488) proveniente de Eliumberrum, atual Auch na França - contígua, não há por que duvidar, ao local onde a cadelinha foi carinhosamente enterrada.

Quam dulcis fuit ista, quam benigna, quae cum uiueret in sinu iacebat, somni conscia semper et cubilis. O factum male, Myia, quod peristi! Latrares modo si quis adcubaret riualis dominae, licentiosa.

O factum male, Myia, quod peristi!

Altum iam tenet insciam sepulcrum, nec seuire potes nec insilire,
Como foi doce, como foi mansinha, esta que em vida ao colo só dormia, de sono e leito sempre companheira! Ah que desgraça, Mia, que morreste! Latias quando uma rival deitava junto de tua dona, que assanhada. Ah que desgraça, Mia, que morreste! Ignara agora tem-te erguido túmulo, não podes mais rosnar, nem saltitar, 


\section{CIL, 6, 122652a: a própria esposa morta consola o marido.}

Tu qui secura procedis mente, parumper siste gradum, quaeso, uerbaque pauca lege. Illa ego quae claris fueram praelata puellis, hoc Homonoea breui condita sum tumulo, cui formam Paphie, Charites tribuere decorem quam Pallas cunctis artibus erudiit.

Nondum bis denos aetas mea uiderat annos, iniecere manus inuida fata mihi.

Nec pro me queror hoc, morte est mihi tristior ipsa maeror Atimeti coniugis ille mei.

"Sit tibi terra leuis, mulier dignissima uita quaeque tuis olim perfruerere bonis."
Tu que passas confiante um momento detém teu passo, peço, e lê poucas palavras.

Aquela sou, a eleita entre meninas belas que ora jaz - Homonéia - em breve túmulo, a quem a Páfia deu beleza, e graça as Cárites e Palas ilustrou nas artes todas.

Minha idade não vira ainda vinte anos, e invejosa lançou-me o fado a mão.

Não lamento por mim, mais triste que morrer é o luto de Atimeto, meu marido.

"Que a terra seja leve, esposa muito digna da vida e de teus bens ter desfrutado."

27. CIL, 6, 122652b: O marido responde à esposa.

\footnotetext{
Si pensare animae sinerent crudelia fata et posset redimi morte aliena salus, quantulacumque meae debentur tempora uitae, pensassem pro te, cara Homonoea, libens.

At nunc quod possum, fugiam lucemque deosque, ut te matura per Styga morte sequar.

"Parce tuam, coniux, fletu quassare iuuentam fataque maerendo sollicitare mea.

Nil prosunt lacrimae nec possunt fata moueri. Viximus, hic omnis exitus unus habet.

Parce: ita non unquam similem experiare dolorem et faueant uotis numina cuncta tuis.

Quodque mihi eripuit mors immatura iuuentae, id tibi uicturo proroget ulterius".
}

Se o duro fado a alma barganhar deixasse e redimir na morte a vida alheia, meu restinho de vida de bom grado a ti, Homonéia querida, eu te daria.

Mas posso agora só à luz fugir, aos deuses, e no Estige seguir-te, morto enfim.

"Deixa de consumir no choro a juventude, esposo, e de buscar na dor meu fim.

Não logram nada lágrimas, não dobram fados: não vivo, é este, um só, o fim de tudo.

Deixa: que nunca mais padeças dor igual e os votos teus que os deuses todos ouçam. Quanto de juventude a morte me tolheu, tão cedo, a ti, que vivas mais, conceda.

\section{Epigrama erótico}

\section{Pseudo-Sêneca (séc.I d.C.), 65.}

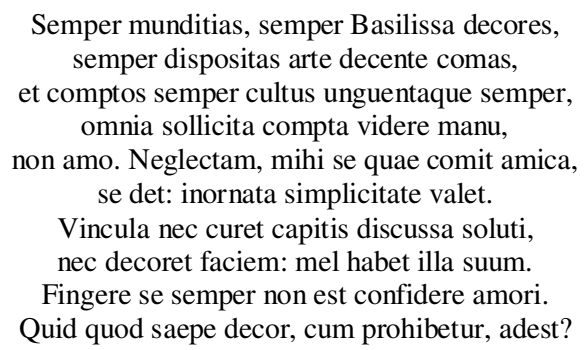

Vincula nec curet capitis discussa soluti, nec decoret faciem: mel habet illa suum. Fingere se semper non est confidere amori. Quid quod saepe decor, cum prohibetur, adest?

Sempre o correto, sempre, Basilissa, enfeites, sempre os cabelos muito bem penteados, pintado sempre o rosto, unções, perfumes sempre, tudo arrumado ver da mão zelosa não amo; em desalinho venha a amante e a mim se dê: no simples desadorno é linda.

Não cuide em frouxo laço dos cabelos soltos e que ela à minha frente lave o rosto.

O sempre se adornar é não confiar no amor: reprimido, não surge amiúde o belo?

\section{Epigrama jocoso}

29. Apêndice Virgiliano, Catalepton, 10 (séc. I-II d.C. ?): paródia anônima do famoso poema 4 de Catulo: consta da Appendix Vergiliana (Apêndice Virgiliano), onde foram reunidos os poemas outrora atribuídos a Virgílio. No poema de Catulo, o idoso já retirado conta façanhas passadas, o vigor do corpo é compensado pela sabedoria e pela correta palavra, não sem alguma jactância, como a retórica e a poética antiga 
reconheciam próprias do caráter do ancião. No rebaixamento paródico, a personagem é muleteiro que, enriquecido (senta-se em assentos elefantinos, isto é, de marfim, das baixas autoridades municipais, vv. 23-24), mudou o nome e, aposentado, relata antigas façanhas. Mântua (v. 4), Bríxia e Cremona (v. 12) são cidades da Gália Cisalpina. Trifão (v. 6) e Cérulo (v. 7) são muleteiros concorrentes que também prosperaram: o primeiro é escravo grego liberto, como o nome indica; o outro é proprietário de imóveis e aluga cômodos à camada baixa do povo. É de notar, além do rebaixamento paródico, o emprego, com sentido diferente e vulgar, de palavras que Catulo utilizara: insula, em Catulo (v. 7) significa "ilha", uma das Cíclades; na paródia significa "casario", "cortiço"; iugo (v. 10) de iugum, em Catulo (v. 11) significa "cume", "cimo" do monte Citoro; na paródia significa "jugo", "trela" feita com a madeira dali provinda.

\footnotetext{
Sabinus ille, quem uidetis, hospites ait fuisse mulio celerrimus, neque ullius uolantis impetum cisi nequisse praeterire, siue Mantuam opus foret uolare siue Brixiam, et hoc negat Tryphonis aemuli domum negare nobilem insulamue Caeruli, ubi iste post Sabinus ante Quintio bidente dicit attondisse forcipe comata colla, ne Cytorio iugo premente dura uulnus ederet iuba. Cremona frigida et lutosa Gallia, tibi haec fuisse et esse cognitissima ait Sabinus: ultima ex origine tua stetisse dicit in uoragine, tua in palude deposisse sarcinas et inde tot per orbitosa milia iugum tulisse, laeua siue dextera strigare mula siue utrumque coeperat neque ulla uota semitalibus deis sibi esse facta, praeter hoc nouissimum, paterna lora proximumque pectinem. Sed haec prius fuere: nunc eburnea sedetque sede seque dedicat tibi, gemelle Castor et gemelle Castoris.
}

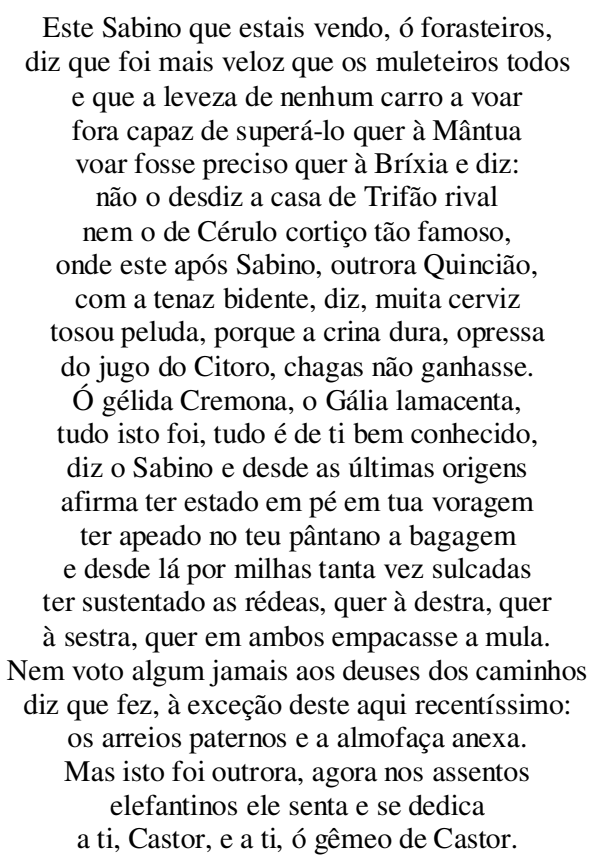

Epigrama invectivo

30. Ausônio (c. 310-c. 393 d.C.), Epigramas, 79: Ausônio, poeta cristão (c. $310-c$. 393 d.C.), já não ratifica as práticas amorosas dos pagãos, embora não se furte da linguagem. "Herdeiro de Hércules" (Herculis heredi, v. 3) na mitologia é Filoctetes, legatário das armas de Hércules. Como Filoctetes permaneceu 10 anos sozinho na ilha de Lemnos, a privação, isto é, a abstinência sexual (egestas, v. 3), levou-o, subentendese, à masturbação. Lúcio Afrânio (Afrani, v. 4) foi comediógrafo do fim do século II e início do I a.C., que segundo Quintiliano (Instituições Oratórias, 10, 1, 100) em suas comédias levou à cena "torpes amores de meninos" (puerorum foedis amoribus), ou seja, o amor pederástico e a conseqüente penetração anal, ratificada e especificada para mulher em "numa gruta e noutra" (utramque cauernam, v. 7), bem entendido, penetração vaginal e anal. A luxúria da boca (capitalis luxus, literalmente "luxúria da cabeça", v. 5) diz respeito à felação, que segundo Ausônio era comum em Nola, cidade da Campânia. 
Praeter legitimi genialia foedera coetus, repperit obscenas ueneres uitiosa libido, Herculis heredi quam Lemnia suasit egestas, quam toga facundi scaenis agitauit Afrani, et quam Nolanis capitalis luxus inussit. Crispa tamen cunctas exercet corpore in uno: deglubit, fellat, molitur per utramque cauernam, ne quid inexpertum frustra moritura relinquat.
Além de amplexos lídimos do casamento, obscenos gozos quis a viciosa libido

que a Lêmnia privação deu ao herdeiro de Hércules; que a toga do facundo Afrânio pôs em cena; que a luxúria da boca aos Nolanos calcou. Mas Crispa tudo faz num corpo só: descasca e chupa e é socada numa gruta e noutra por nada em vão deixar na morte sem provar.

\section{Epigrama erótico}

\section{Ausônio (c. 310-c. 393 d.C.), Epigramas, 50.}

Uxor uiuamus ut uiximus et teneamus nomina, quae primo sumpsimus in thalamo; nec ferat ulla dies, ut commutemur in aeuo, quin tibi sim iuuenis tuque puella mihi.

Nestore sim quamvis provectior aemulaque annis uincas Cumanam tu quoque Deiphoben, nos ignoremus quid sit matura senectus. Scire aeui meritum, non numerare decet.
Mulher, vivamos qual vivemos e tenhamos os nomes que à primeira noite usamos.

Não haja um dia só, bem que mudemos sempre, Que não me digas "jovem" e eu, "menina".

Mais velho embora que Nestor, rival que venças em anos a Deífobe de Cumas,

a velhice madura ignoremos: o mérito convém saber do tempo, não a soma. 